\title{
Causes and Countermeasures of Hubei Local College Sports Teacher Burnout Phenomenon
}

\author{
Yuqun CHEN Yanming PENG \\ Hubei Normal University \\ Huangshi, 435002 China
}

\begin{abstract}
The nature of the differences between schoolteacher burnout of depersonalization and low sense of accomplishment both had a significant impact. Marital status on the emotional exhaustion dimension had significant differences. Emotional exhaustion, depersonalization and low sense of accomplishment have differences in 3 age dimensions. Emotional exhaustion, depersonalization and low sense of achievement have differences in the time of three dimensions. A counselor at a low sense of accomplishment dimension Kai shows significant differences. Low achievement among different dimensions appears qualifications significant differences. PE teachers in colleges with different titles appear emotional exhaustion and personal accomplishment reduces in two dimensions of significant differences; teachers to teach a few lessons on the various dimensions of teacher burnout are significantly different; whether leading case teacher Burnout depersonalization and low achievement scores are in two dimensions significantly affected. This paper from the personal, social point and that of schoolteachers is to discuss in three aspects of college sports teacher the causes of burnout, and then to put forward that PE teachers in local colleges and universities should strengthen the quality of physical education teachers.
\end{abstract}

Keywords- Local Colleges; PE Teachers; Burnout

\section{INTRODUCTION}

Burnout (Job burnout) refers to as the emotional weight of the individual in the work produced by the depletion of physical and mental fatigue, reduction of job commitment, job satisfaction and other negative state of decline. Burnout is not a minority phenomenon abnormal reaction, but to help others in the industry is a common phenomenon situation. Feidengboge in 1974 first proposed the "burnout," he says burnout is one of the most easily emotional exhaustion symptoms that appears in helping the industry. Then Maslach and others respond to the work of the long-term emotional and interpersonal stressors arising from psychological syndrome called burnout. It is generally believed that burnout is an extreme reaction of individuals that cannot successfully cope with work pressure, and is accompanied by an individual under prolonged pressure that generated emotional experience, attitude and behavior of exhaustion. Representative of the clinical view is Freudenberge, he precludes the use of the clinical approach to understanding burnout. Burnout is a high intensity of work that ignores their own personal needs and is intended to bear the fatigue caused by the state, there is too much effort to reach unrealistic expectations of some personal or social outcomes. Feidengboge's burnout process focuses on the description of the etiology, symptoms, and clinical course and treatment recommendations. He put on a wide range of social theory burnout situations, changes in our values because we are unsure of the life goals, which in turn created the conditions for the generation of burnout. Social psychology point of view is representative of Maslach's poem and Pines. Compared with Feidengboge Mahler poetry and research on burnout Pace employs methods of social psychology. Mahler poem from a comprehensive perspective of burnout is defined, most scholars agree that this is one of the many acceptances. In Mahler's poem, the burnout is defined as a state of emotional exhaustion, including negative self-concept, attitude and treat clients with indifference. This is an indicator of current empirical research in Western countries that is generally adopted. Specifically Here are three levels of burnout: emotional exhaustion (emotional exhaustion), refers to the process of interaction with the work of others, individuals feel a lack of energy and emotions that have run out of resources, lack of enthusiasm for the work, and it is often accompanied by frustration and tension. Therefore, emotional exhaustion is a contact with others, feeling emotionally exhausted. Depersonalization (depersonalization), also known as "depersonalization" refers to the process of interaction with others, an individual with no emotion and indifference to the way around the crowd responded to the work object or organization exhibiting emotional apathy, alienation and negative attitudes. Performance at work to reduce exposure or reject students will have no feelings of students as object, appellation with contempt color of the title, with tabbed language to describe individual students, colleagues often hold suspicious attitude. Meanwhile, the personal quality of life is also often limited to a low level. Low achievement (lack of personal accomplishment), that refers to the process of interaction with others, personal feelings for their ability is to lower job satisfaction and negative evaluation of their tendency to self-evaluate the individual meaning and value is reduced, including cooperation with others when capacity is insufficient to complete the work generated by the low sense of accomplishment. Teachers began to feel that their work is no longer what is worth doing, feeling that they cannot bring more changes to the student's life, and tend to self-pan loss, 
the work is not successful due to lack of capacity on their own, so generate a sense of helplessness.

\section{RoOT CAUSE OF LOCAL TEACHERS' JOB BURNOUT}

Root cause of teacher burnout abroad, mainly from three aspects are described, namely social causes, organizations and individuals to the root causes. Social roots of teacher burnout: the success or failure of education related to the future development of society, and therefore, most of the world countries are to maintain high educational requirements and expectations. Ask too many expectations tend to make teachers feel pressure to produce; Britain emerged due to various problems and condemned the tendency of teachers. As for workload: class size increases, which greatly strengthened the workload of teachers, giving them a burnout. Many teachers feel in British "weekends have been a distant past." As for student problems: students' misbehavior, indifference about things, lack of enthusiasm for learning materials, which are easy to make teachers produce burnout. It is closely related to the weary and the deterioration of relations between teachers and teachers. Role conflict and role ambiguity: In terms of organization, significant factors affecting teacher burnout is the role conflict and role ambiguity. When individuals are faced with a conflict situation but are expected to make the role of behavior, role conflict occurs. In this case, if an individual cannot properly reconcile this dissonance, the pressure will be generated. The role ambiguity refers to the individual because of the lack of a clear and consistent understanding of its occupation authority, obligations, responsibilities and feeling of the work cannot be qualified, this role also easily lead to pressure fuzzy production. The degree of freedom and autonomy: Burnout following conditions will reduce the number of teachers: First, when individual teachers feel more freedom and more autonomy in teaching; the second is when the teacher convinced them to participate in school decisionmaking; third, when teachers feel that their organizations have a school for teachers when teaching incentives reward and punishment. Personal roots of teacher burnout: "The control is due to the outside world," the teacher burnout is more likely, they usually believe in fate, luck, I believe that would force more powerful things that happened to them in charge. In addition, some scholars believe that when some teachers feel they need to be able to meet senior at work, they will rarely produce burnout. Foreign findings give us a lot of information. First, many of the country's economic level material conditions on our country, but there are still teachers' burnout phenomenon, suggesting that the only reason for the material aspects of economic factors do not lead to burnout. So when exploring the root causes of teacher burnout, it must be multifaceted investigation and in-depth thinking. Second, teachers' burnout comes from the pressure. Therefore, teachers' self-mediation is important, however, the pressure of the objective existence of incentives, teachers rely solely on individual effort that cannot solve all the problems, only the school, the community, the country to meet, timely and appropriate to take appropriate measures to put teachers' professional Burnout slowed to a minimum.
University administrators must first close the teachers, so that teachers get involved in school management, with a deep understanding of the basic requirements of teachers. So not only can improve teachers 'burnout phenomenon, but also improve teachers' enthusiasm for the work, so that teachers work with the greatest enthusiasm into teaching work, which would also help university administrators from the grassroots to understand the problems faced by the school building that is conducive to the development and construction of the school. Relationship is another important factor. In addition, good relationships between colleagues, so that teachers feel comfortable at work, which can effectively alleviate the pressure of work, improve efficiency, and enhance the cohesion among colleagues. Part of college physical education teachers at work did not establish good relationships between colleagues and there are different degrees of estrangement, interpersonal tensions may affect motivation and enthusiasm PE teacher at work, resulting in a heavy heart, unable to concentrate on teaching job, having a negative impact on physical education. Among teachers in the daily work and life should strengthen exchanges, not to escape when they encounter problems at work, they will actively and positively to ask colleagues, when colleagues have difficulty reaching out initiative, which helps to establish good interpersonal relationship to form a good working atmosphere, help teachers work ethic get improved. In colleges and universities, schools and teachers are the bridge between the students, the relationship between students and teachers deal is also very critical. PE teachers and parents, there is a gap between the students and to some extent, the lack of communication is not conducive to the smooth development of teaching, the teaching profession itself is a career dealing with people, teachers should communicate with students, to get from students' feedback sports teaching, positive improvements in the lesson more exchanges with students. Improve physical education teachers, between teachers and parents relationship sport, physical education teachers and students will not only help alleviate the PE teacher burnout phenomenon, as well as conducive to the smooth conduct of teaching, improve teaching quality, stimulate greater investment in physical education teachers enthusiasm to teaching work.

\section{IMPROVEMENT MEASURES FOR PE TEACHER BURNOUT}

We should continuously improve their overall quality, and actively adjust teacher training to enhance their own personality, to maintain mental health, to a correct understanding of the working pressure, optimistic, openminded attitude to face the job. Let the students in a healthy environment to grow, first teacher should have a good attitude, establish the correct teaching ideas and actively work of faith, cultivate the spirit of selfless dedication to students, prevention of burnout generation is very important. Teachers should correctly understand the burnout, when they found themselves professional burnout when there appear to actively analyze the reasons for their own burnout, actively seeking ways to relieve a variety of burnout. Teachers should recognize the difficulties in their jobs that may be 
encountered and restricted, a correct understanding of their own, neither arrogant nor too low self-esteem, discovers their strengths in the teaching process, weaknesses, and efforts to overcome their deficiencies. As a teacher, you should establish a high standard of professional ethics and professional belief in the necessary work of self-adjustment. We should have prevention and mitigation of college sports teacher burnout measures during the study of this subject which through questionnaires and statistical analysis. There are some problems to test teachers' burnout situation, but it is not very serious, but the situation of college sports teacher burnout is very general. The emergence of emotional exhaustion, low sense of accomplishment have bad mood. According to the survey, this study shows that the factors leading to produce PE teacher burnout that is multifaceted, teacher burnout wants to solve the current situation, not simply propose several measures that can be resolved smoothly. From the community, schools, teachers themselves many aspects, they should work together to complement each other, to be able to successfully solve this problem.

Raise the social awareness, improve the treatment of teachers college teachers who are entrusted with the task of education of contemporary college students, along with social and economic development that requires college students to have a higher overall quality, which requires college students not only to have a solid theoretical knowledge, but also have a strong physique. All along, the majority of parents and students agree that physical education curriculum only "minor subjects" and it did not get enough attention. To improve college sports teacher burnout problems is to be given to the physical education curriculum on the total social enough attention, "the knowledge lightweight" must be carried out to improve the current situation. PE teacher should pay a lot of physical effort to improve the quality of teaching, but also hope to get parental approval, social recognition. Social work teachers and parents to give full recognition, teachers can have more enthusiasm into teaching work. Social status of physical education teachers, the same should attract enough attention to the community.

\section{CONCLUSIONS}

Local College Physical Education Teachers at this stage of burnout situation is more serious. In terms of coping burnout, teachers have taken a large part of negative coping. Actively respond to the emotional exhaustion and depersonalization presents a very significant negative correlation. Negative response is very significant positive correlation with emotional exhaustion and depersonalization rendering. This paper presents strategic proposals to deal with the local College Physical Education Teachers' Burnout.

On the social level: The existence of physical education teachers have more serious burnout, they accordingly should adopt incentives to build scientific ideas to alleviate teacher burnout, encourage education, promote scientific research, scientific assessment, a reasonable allocation, people- oriented, demand respect. We should have emphasis on college physical education and awareness of the importance of physical education: College PE teachers work for the entire higher education, for the overall development of the country. A crucial role in the whole society should be respected, which is to create a society in whole respect, caring, understanding, support social atmosphere of college sports teachers.

On the school level: First, the establishment of democracy and reasonable teacher management system establish a reasonable teacher evaluation system. Combined with the actual situation of physical education teachers, we should establish a scientific and reasonable job evaluation and reward system to ensure that physical education teachers and other teachers have the same treatment. So, it can encourage teachers to show high confidence and motivation to avoid burnout situations.

On the teachers' personal level: Teachers' beliefs and career aspirations are to maintain the mental health of teachers under pressure to ensure that important. "Teachers should establish lofty career aspirations, recognizing the importance of the work they are engaged in educational work for the entire university, recognizing the long-term value in their own work. We should pay attention to the development of education and teaching theory, be concerned about the development of cutting-edge discipline, improve research capacity. By increasing the capacity of the various aspects of teachers teaching and research, it will be handy to treat, it will be more a sense of accomplishment and experience to work fun, but also will prevent and alleviate burnout.

\section{ACKNOWLEDGEMENT}

Fund: Hubei Provincial Department of Education 2012 Humanities and Social Sciences Project (2012323), Hubei Province, education and science "Eleventh Five-Year Plan" of 2010 subjects (2010B080)

\section{References}

[1] Wang Feng. Zhuhai College Sports Teacher Burnout Study [J] Heilongjiang Science and Technology Information, 2009,10: 160-161.

[2] Wang Shouheng. Causes of PE teacher Burnout and Its Strategy [J] Beijing Sport University, 2005,10: 1393-1394 + 1405.

[3] Hao Ming. Studied college burnout and professional self-concept relationship. Henan Sports teacher [D]. Henan University, 2006.

[4] Cao Limin. Middle school PE teachers' vocational weariness under background of reformed PE course explores [J] Wuhan Institute of Physical Education, 2006,03: 106-108.

[5] Jing Ling. Influences College PE teacher burnout - Research on college physical education teachers in Wuhan [J] Wuhan Institute of Physical Education, 2008,11: 82-85.

[6] Wang Xiaofang. PE teacher burnout analytical concept [J] Capital Institute of Physical Education, 2007,03: 36-37 + 43 .

[7] Hao Haitao. College Sports Teacher Burnout working pressure study, and their relationship [J] Sports Sciences, 2007, 06: 111-115 + 120 . 